\title{
Low FOXA1 expression predicts good response to neo-adjuvant chemotherapy resulting in good outcomes for luminal HER2-negative breast cancer cases
}

\author{
Y Horimoto ${ }^{\star}, 1,2$, A Arakawa ${ }^{3}, \mathrm{~N} \mathrm{Harada}^{-S h o j i}{ }^{4}, \mathrm{H} \mathrm{Sonoue}^{3}, \mathrm{Y} \mathrm{Yoshida}^{1}$, T Himuro ${ }^{1}$, F Igari ${ }^{1}$, E Tokuda ${ }^{1}$, \\ O Mamat ${ }^{3}$, M Tanabe $^{1}, \mathrm{O} \mathrm{Hino}^{2}$ and M Saito ${ }^{1}$ \\ ${ }^{1}$ Department of Breast Oncology, Juntendo University School of Medicine, 2-1-1 Hongo, Bunkyo-ku, Tokyo 113-0033, Japan; \\ ${ }^{2}$ Department of Pathology and Oncology, Juntendo University School of Medicine, 2-1-1 Hongo, Bunkyo-ku, Tokyo 113-0033, \\ Japan; ${ }^{3}$ Department of Human Pathology, Juntendo University School of Medicine, 2-1-1 Hongo, Bunkyo-ku, Tokyo 113-0033, \\ Japan and ${ }^{4}$ Division of Cancer, Department of Surgery and Cancer, 1st Floor, ICTEM Building, Hammersmith Hospital, Imperial \\ College London, London W12 ONN, UK
}

Background: FOXA1 expression is a good prognostic marker for endocrine therapy in hormone-positive breast cancer. We retrospectively examined breast cancer patients with luminal human epidermal growth factor receptor 2 (HER2)-negative tumours, as defined by immunohistochemistry, who received neo-adjuvant chemotherapy (NAC) and investigated the relationship between treatment effects and FOXA1 expression.

Methods: Biopsy specimens from 103 luminal HER2-negative tumours were immunohistochemically examined. FOXA1 effects on chemo-sensitivity were also investigated employing in vitro experiments.

Results: FOXA1 and Ki67 expressions independently predicted a pathological complete response (pCR). Knockdown of FOXA1 by siRNA boosted the chemo-effect in oestrogen receptor-positive cells. The Cox hazards model revealed a pCR to be the strongest factor predicting a good patient outcome.

Conclusions: Our present study showed low FOXA1 expression to be associated with a good response to NAC in luminal HER2negative breast cancer. Improved outcomes of these patients suggest that NAC should be recommended to patients with low FOXA1 tumours.

Since the concept of intrinsic subtypes based on gene profiles was introduced (Sørlie et al, 2003; Peppercorn et al, 2008), treatment strategies for breast cancer have changed dramatically. For instance, patients who have luminal human epidermal growth factor receptor 2 (HER2)-negative tumours with lymph-node involvement are more likely to receive only endocrine therapy as adjuvant treatment after surgery (Goldhirsch et al, 2013), while chemotherapy was formerly recommended for such patients according to a global consensus (Goldhirsch et al, 2007).
Luminal HER2-negative tumours are a good indication for endocrine therapy, while the benefits of adjuvant chemotherapy are now considered to be relatively small. This is because the chemoeffect is lower than in other subtypes and, as adjuvant treatment, endocrine therapy is considered to be sufficient for most of these patients. However, we often encounter luminal HER2-negative patients who respond well to neo-adjuvant chemotherapy (NAC) with some even obtaining a pathological complete response (pCR). In fact, a number of studies have revealed that a sub-population, 
who would benefit from chemotherapy, certainly exists among luminal HER2-negative breast cancer patients (Fasching et al, 2011; Denkert et al, 2013; Horimoto et al, 2014). Thus, clinically, it is crucial to identify this sub-population.

FOXA1, a member of the forkhead class of DNA-binding proteins, is crucial for oestrogen-induced oestrogen receptor (ER) binding and subsequent transcription (Ross-Innes et al, 2012; Bernardo et al, 2013). Recent thorough investigations have revealed that FOXA1 expression correlates with less-aggressive tumour characteristics and good outcomes (Badve et al, 2007; Wolf et al, 2007; Habashy et al, 2008; Thorat et al, 2008; Hurtado et al, 2011; Ross-Innes et al, 2012). However, the relationship between FOXA1 expression and the response to chemotherapy is still unclear. We hypothesised that a tumour with low FOXA1 expression might respond well to chemotherapy because FOXA1 expression is characteristic of luminal A-like tumours (Badve et al, 2007). In this study, we retrospectively examined breast cancer patients with luminal HER2-negative tumours, as defined by immunohistochemical (IHC) results, who received NAC and investigated the relationship between treatment effects and FOXA1 expression.

\section{MATERIALS AND METHODS}

Clinical samples. There were 220 patients with invasive breast cancer who received NAC and underwent surgery during the 2006 through 2008 period at our institution. They were given CEF (C: cyclophosphamide: $500 \mathrm{mg} \mathrm{m}^{-2}$, E: epirubicin: $75-100 \mathrm{mg} \mathrm{m}^{-2}, \mathrm{~F}$ : 5-fluorouracil: $500 \mathrm{mg} \mathrm{m}^{-2}$, tri-weekly, 4 cycles) followed by taxane (paclitaxel: $80 \mathrm{mg} \mathrm{m}^{-2}$, weekly, 12 treatments; or docetaxel: $75 \mathrm{mg} \mathrm{m}^{-2}$, tri-weekly, 4 cycles). We retrospectively examined 103 patients with luminal HER2-negative tumours among these 220 cases for tumour characteristics and biomarkers. Clinicopathological features of the 103 patients are shown in Table 1. All patients were ER positive. Proportions receiving various chemotherapeutic regimens: $89 \%$ of the 103 patients received CEF followed by taxane, $2 \%$ only taxane, and $9 \%$ only CEF. Following surgery, 101 of the 103 patients (98\%) had been given adjuvant endocrine therapy,

Table 1. Clinicopathological features of all 103 patients

\begin{tabular}{|c|c|}
\hline Age (mean) & $51.4(22-78)$ \\
\hline \multicolumn{2}{|l|}{$c T^{a}$} \\
\hline T1 & 15 \\
\hline T2 & 77 \\
\hline T3 and 4 & 11 \\
\hline \multicolumn{2}{|l|}{$\mathrm{cN}^{\mathrm{a}}$} \\
\hline+ & 72 \\
\hline- & 31 \\
\hline \multicolumn{2}{|l|}{ Structure } \\
\hline Ductal & 98 \\
\hline Lobular & 5 \\
\hline \multicolumn{2}{|l|}{ NG } \\
\hline High & 11 \\
\hline Low & 90 \\
\hline \multicolumn{2}{|l|}{ PR } \\
\hline Positive & 67 \\
\hline Negative & 36 \\
\hline \multicolumn{2}{|l|}{ Ki67 ${ }^{b}$} \\
\hline High & 20 \\
\hline Low & 83 \\
\hline \multicolumn{2}{|c|}{ 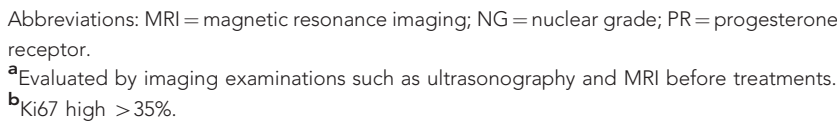 } \\
\hline
\end{tabular}

aromatase inhibitors, or selective ER modulators $+/-$ LHRH agonists.

This study was carried out with approval from the ethics committee of Juntendo University Hospital and written informed consent was obtained from patients whose data have been included in this study.

Pathological examination and IHC. Pathological examinations were carried out centrally by two pathologists at Juntendo University School of Medicine. Nuclear grade (NG) was judged based on the modified Bloom-Richardson histological grades. Chemotherapy effects were determined employing operative specimens and we defined pCR as invasive nest disappearance based only on the primary breast tumour, that is, without lymphnode evaluation.

Immunohistochemistry was performed on biopsy specimens before NAC in this study to avoid possible chemotherapy-related effects on protein expressions observed in surgical specimens after NAC. The fixation and staining processes were previously described in detail (Horimoto et al, 2014). Cells positive for nuclear Ki67 were counted in at least 500 cancer cells in one hot spot for each of the biopsy specimens. Oestrogen receptor and progesterone receptors (PRs) were assessed semi-quantitatively and reported as positive when more than $10 \%$ of the nuclei of cancer cells showed staining. Human epidermal growth factor receptor 2 was judged to be positive if more than $10 \%$ of tumour cells showed strong staining of the entire cell membrane, or HER2/neu gene amplification was confirmed by fluorescence in situ hybridisation. In this study, we excluded such HER2-positive tumours.

FOXO3a is a downstream target of the PI3K/Akt pathway and negatively regulates cell fate (e.g., apoptosis and cell-cycle arrest) (Ho et al, 2008, 2012). We employed this protein to evaluate Akt signals that might reflect chemo-effects in a manner different from that of the ER signal pathway, although there are contradictory reports about the correlation between nuclear localisation of FOXO3a and patient outcomes (Peck et al, 2013). We defined FOXO3a as being positive when more than $50 \%$ of cells showed staining for this protein in the nucleus and/or the cytoplasm. As to FOXA1, we determined a cutoff value allowing us to judge a specimen as being positive with consideration of the chemo-effect, as shown in the Results section.

Details of antibodies; ER: rabbit monoclonal, clone SP1 (Ventana, Tucson, AZ, USA), PR: rabbit monoclonal, clone 1E2 (Ventana), HER2: rabbit monoclonal, clone 4B5 (Ventana), Ki-67: mouse monoclonal, clone MIB-1 (Dako, Tokyo, Japan), FOXA1: rabbit polyclonal, clone ab23738 (Abcam, Tokyo, Japan), FOXO3a: rabbit polyclonal, clone \#9467 (Cell Signaling Technology, Tokyo, Japan).

Cell culture. The human breast carcinoma cell lines MCF-7, SK-BR-3, and T-47D were purchased from the American Type Culture Collection and maintained in RPMI-1640 medium supplemented with $10 \%$ fetal bovine serum and $100 \mathrm{Uml}^{-1}$ penicillin/streptomycin in a humidified incubator at $37^{\circ} \mathrm{C}$. Paclitaxel was obtained from Bristol-Myers Squibb (New York, NY, USA) and a paclitaxel-resistant breast cancer cell line, MCF-7$\mathrm{PTX}^{\mathrm{R}}$, was established by chronic exposure of the parental drugsensitive MCF-7 to stepwise increases in paclitaxel concentrations, until a resistance concentration of $5 \mathrm{nmoll}^{-1}$ was achieved.

Gene silencing with siRNAs. For gene silencing, Stealth RNAi siRNA against FOXA1 (HSS104880) was purchased from Life Technology (Tokyo, Japan). Control siRNA (sc-37007, Santa Cruz Biotechnology, Dallas, TX, USA) was used as a negative control. Transient transfection of siRNA was carried out using siLentFect lipid reagent (Bio-Rad, Hercules, CA, USA) according to the manufacturer's instructions. Two $\times 10^{5}$ cells were plated into 6well plates $24 \mathrm{~h}$ before transfection. Cells were incubated with the 
final concentration $(20 \mathrm{nM})$ of siRNA with siLentFect for $48 \mathrm{~h}$ and then corrected for the following examinations.

Western blot. Western blotting was performed on whole-cell extracts by lysing cells in SDS/PAGE buffer as previously described (Ho et al, 2009). Antibodies to FOXA1 (ab23738, Abcam), $\alpha$ tubulin (B-5-1-2, Sigma-Aldrich, Tokyo, Japan), ER (sc543, Santa Cruz Biotechnology), PR (clone 16, Leica, Milton Keynes, UK), and CK5/6 (D5/16 B4, Dako) were used. Primary antibodies were detected using HRP-conjugated anti-mouse or anti-rabbit IgG (Dako) and visualised using the ECL detection system (Merck Millipore, Billerica, MA, USA).

Proliferation assay. To determine cell proliferation, a Cell Counting Kit-8 (Dojindo Laboratories, Kumamoto, Japan) was purchased and employed at the indicated time points, according to the manufacturer's instructions with the use of a microplate reader.

Statistical analysis. Statistical analyses were performed using JMP 10.0.1 statistical software (SAS Institute Inc., Cary, NC, USA). Associations between chemo-effects and clinicopathological parameters were evaluated using Fisher's exact test. For comparison of mean values such as those of patient age, examinations of unpaired data were carried out with the two-sided Student's $t$-test. The optimal FOXA1 cutoff value predicting pCR was determined using Receiver Operating Characteristic (ROC) curve analysis. The curve was created by plotting the true positive fraction (= sensitivity, equivalent to $\mathrm{pCR}$ rate herein) on the $\mathrm{y}$-axis $v s$ the false positive fraction (=1-specificity) on the $\mathrm{x}$-axis for each FOXA1 value tested in the range from $1 \%$ to $100 \%$. With this statistical method, the best possible prediction point is in the upper left corner, with coordinates (of 0 and 1) in the ROC space, and is referred to as the perfect classification. We determined the optimal FOXA1 value to be that nearest to the perfect classification. The logistic regression model was constructed using the backward selection procedure in an attempt to discover the predictors of pCR. Survival curves were estimated by the Kaplan-Meier method with a log-rank test to assess significance. A multivariate Cox proportional hazard regression model was used to evaluate any independent prognostic effect of the variables with a $95 \%$ confidence interval. A $P$-value of $<0.05$ was considered to indicate a statistically significant difference.

\section{RESULTS}

PR-negative and/or Ki67-high tumours showed good responses to NAC. The pCR rate for the 103 luminal HER2-negative tumours was $9 \%$ ( 9 cases). The clinicopathological features according to chemo-effect are shown in Table 2. Progesterone receptor-negative tumours showed good responses to the treatments given $(P<0.05)$, while age, tumour size, structure, and NG were not associated with treatment responses. Tumours with high Ki67 expression also showed good responses to NAC $(P<0.05)$ when the comparison was made based on Ki67 higher and lower than $35 \%$, the cutoff value that we considered to distinguish good from poor chemo-effects in luminal HER2-negative tumours in our previous study (Horimoto et al, 2014).

FOXA1 predicts good effect of NAC. Next, we evaluated FOXA1 and FOXO3a expressions in biopsy specimens by IHC. All samples expressed FOXA1 (1-100\%) and median expression was $76 \%$ (details shown in Supplementary Figure 1). There is no generally accepted cutoff value indicating that a specimen is positive for FOXA1 and a wide range of values, 10$72 \%$, has been used (Hisamatsu et al, 2012; Tominaga et al, 2012; Kawase et al, 2013; Sasahara et al, 2014). As shown in Supplementary Figure 1, pCR was observed more frequently in low FOXA1 tumours. Thus, we decided to first determine a cutoff value for FOXA1 distinguishing between pCR and nonpCR, and employ this value to decide whether FOXA1 expression was high or low. Receiver Operating Characteristic curve analysis revealed ' $67 \%$ ' to be the FOXA1 cutoff value that best distinguished between pCR and non-pCR cases (Supplementary Figure 2). Thus, in the current study, we defined FOXA1 expression as high when more than $67 \%$ of cancer cells showed staining.

Fisher's exact test revealed that tumours with low FOXA1 expression did indeed show good responses to NAC $(P<0.01)$ (Table 2). There was, however, no trend between chemo-effect and FOXO3a expression regardless of its localisation (i.e., nucleus and/ or cytoplasm). Next, we employed a multivariate logistic regression model to identify factors predicting chemo-effect. Only FOXA1 and Ki67 were related to the efficacy of chemotherapy $(P<0.05)$,

Table 2. Clinicopathological features and responses to NAC in luminal HER2-negative tumour cases

\begin{tabular}{|c|c|c|c|}
\hline & pCR & Non-pCR & $P$-value \\
\hline$n$ & 9 & 94 & \\
\hline Age (mean) & $52.7(22-78)$ & $51.2(29-72)$ & 0.72 \\
\hline cT & & & 0.49 \\
\hline $\mathrm{T} 1$ & 3 & 12 & \\
\hline $\mathrm{T} 2$ & 6 & 71 & \\
\hline vT3 and 4 & 0 & 11 & \\
\hline Structure & & & 0.92 \\
\hline Ductal & 9 & 89 & \\
\hline Lobular & 0 & 5 & \\
\hline NG & & & 0.30 \\
\hline High & 2 & 9 & \\
\hline Low & 8 & 82 & \\
\hline$P^{*}$ & & & 0.012 \\
\hline Positive & 2 & 56 & \\
\hline Negative & 7 & 27 & \\
\hline $\mathrm{Ki} 67 *$ & & & 0.011 \\
\hline High & 5 & 14 & \\
\hline Low & 4 & 79 & \\
\hline FOXA 1 ** & & & $<0.01$ \\
\hline High & 2 & 67 & \\
\hline Low & 7 & 27 & \\
\hline FOXO3a (nucleus) & & & 0.66 \\
\hline Posittive & 5 & 54 & \\
\hline Negative & 2 & 16 & \\
\hline FOXO3a (cytoplasm) & & & 0.32 \\
\hline Posittive & 1 & 3 & \\
\hline Negative & 6 & 67 & \\
\hline \multicolumn{4}{|c|}{ 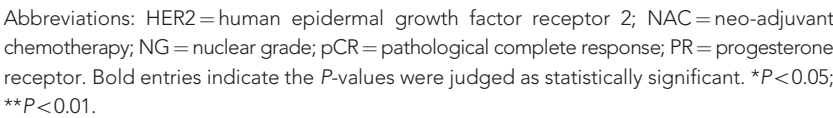 } \\
\hline
\end{tabular}

Table 3. Logistic model for predicting PCR

\begin{tabular}{|c|c|c|}
\hline Variables & OR & $P$-value \\
\hline FOXA1* (low vs high) & 16.2 & 0.030 \\
\hline Ki67* (high vs low) & 11.4 & 0.037 \\
\hline FOXO3a ${ }^{a}$ (negative vs positive) & 5.75 & 0.24 \\
\hline PR (negative vs positive) & 2.69 & 0.34 \\
\hline NG (high vs low) & 1.88 & 0.64 \\
\hline \multicolumn{3}{|c|}{$\begin{array}{l}\text { Abbreviations: } N G=\text { nuclear grade; } P C R=\text { pathological complete response; } P R=\text { progesterone } \\
\text { receptor; } O R=\text { odds ratio. Bold entries indicate the } P \text {-values were judged as statistically } \\
\text { significant. }{ }^{*} P<0.05 \text {. } \\
{ }^{a} \text { Cytoplasm. }\end{array}$} \\
\hline
\end{tabular}


A

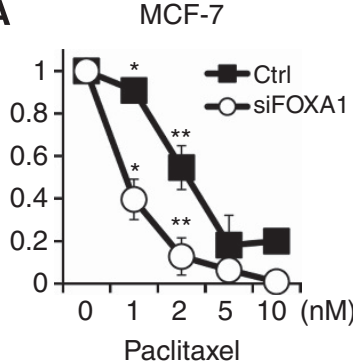

T-47D

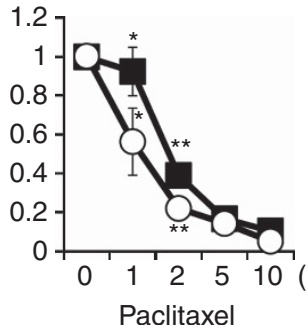

T-47D

B

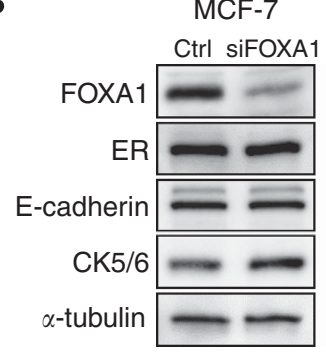

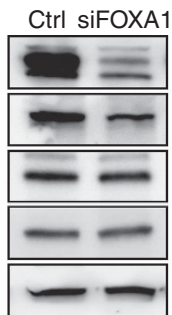

SK-BR-3

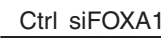

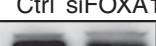

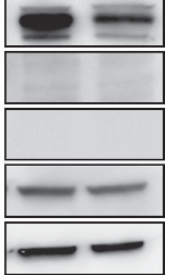

SK-BR-3

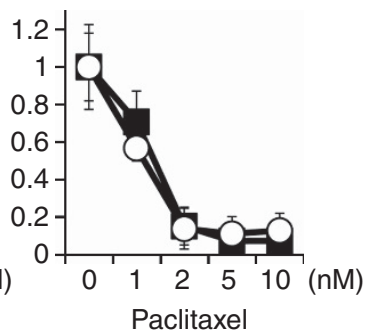

C

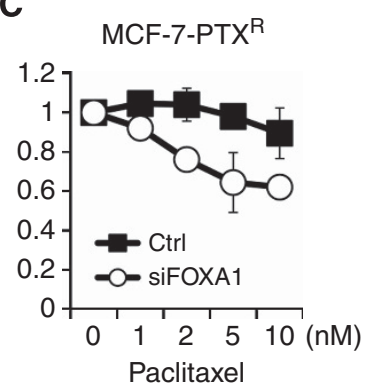

Figure 1. FOXA1 knockdown boosts the efficacy of paclitaxel only in ER-positive breast cancer cells. MCF-7, T-47D, and SK-BR-3 cells were treated with paclitaxel for $96 \mathrm{~h}$ after knockdown of FOXA1 by siRNA. (A) Proliferation assay revealed that FOXA1 suppression enhances responses to chemotherapy in MCF-7 and T-47D, both hormone-positive cell lines. This trend was not observed in hormone-negative SK-BR-3 cells.

(B) Western blot showed that FOXA1 suppression induces MCF-7 cells to express more CK5/6, indicating that these cells have an increased basal propensity. However, this phenomenon was not seen in T-47D. Vimentin is not shown here since none of the three cell lines expressed this protein. (C) The effects of FOXA1 knockdown were also seen in paclitaxel-resistant MCF-7-PTXR cells, suggesting that resistance to chemotherapy had been overcome. ${ }^{\star} P<0.05,{ }^{\star *} P<0.01$.

that is, NG, PR, and cytoplasm staining of FOXO3a were not (Table 3).

FOXA1 knockdown boosts the efficacy of chemotherapy in breast cancer cells. Next, we investigated the effect of FOXA1 on chemo-sensitivity in vitro. MCF-7, T-47D, and SK-BR-3 cells were treated with paclitaxel for $96 \mathrm{~h}$ after knockdown of FOXA1 by siRNA (Figure 1). Proliferation assay revealed that FOXA1 suppression enhances responses to chemotherapy in MCF-7 and T-47D, both hormone-positive cell lines $(P<0.01)$ (Figure $1 \mathrm{~A})$. This trend was not observed in hormone-negative SK-BR-3 cells.

Western blot showed that FOXA1 suppression induces MCF-7 cells to express more CK5/6, markers of basal-type breast cancer, indicating that these cells have an increased basal propensity (Figure 1B). However, this phenomenon was not seen in T-47D. We also speculated that induction of epithelial mesenchymal transition (EMT), as previous studies have suggested (Liu et al, 2005; Williamson et al, 2005), might have occurred. However, no changes in EMT markers (e.g., E-cadherin and vimentin) were observed in any of the cells at the protein level. Interestingly, the effects of FOXA1 knockdown were also seen in paclitaxel-resistant MCF-7-PTX ${ }^{\mathrm{R}}$ cells, suggesting that resistance to chemotherapy had been overcome (Figure 1C).

Patient outcomes. In all, 24 patients (23\% of the 103 ) developed recurrences and 12 of these 24 died due to breast cancer during the median 63-month observation period. We performed multivariate statistical analyses with the Cox proportional hazards model to identify factors predicting patient outcomes. As shown in Table 4, pCR was the only factor predicting good disease-free survival (DFS) and overall survival (OS) for patients $(P<0.01)$. All patients who obtained $\mathrm{pCR}$ have remained free of recurrence. FOXA1 was related only to DFS $(P<0.05)$, while PR was also related to OS $(P<0.05)$.

Next, Kaplan-Meier curves of patient outcomes were drawn according to chemo-effect and FOXA1 expression (Figure 2). Patients who obtained pCR showed better DFS and OS than the
Table 4. Cox proportional hazard model for predicting patient outcomes

\begin{tabular}{|c|c|c|c|c|c|}
\hline \multicolumn{4}{|c|}{ DFS } & \multicolumn{2}{|c|}{ OS } \\
\hline Variables & HR & $P$-value & Variables & HR & $P$-value \\
\hline $\mathrm{pCR} \mathrm{R}^{\star \star}$ & $9.3 \times 10^{-5}$ & $<0.01$ & $\mathrm{pCR}^{\star \star}$ & $7.7 \times 10^{-6}$ & $<0.01$ \\
\hline FOXA1* & 2.37 & 0.049 & PR & 5.07 & 0.010 \\
\hline PR & 2.10 & 0.09 & NG & 6.62 & 0.06 \\
\hline $\mathrm{pN}$ & 1.82 & 0.20 & FOXA1* & 2.91 & 0.08 \\
\hline Age & 0.97 & 0.12 & Age & 0.96 & 0.20 \\
\hline \multicolumn{6}{|c|}{$\begin{array}{l}\text { Abbreviations: } \mathrm{DFS}=\text { disease-free survival; } \mathrm{HR}=\text { hazard ratio; } \mathrm{NG}=\text { nuclear grade; } \\
\mathrm{OS}=\text { overall survival; } \mathrm{PCR}=\text { pathological complete response; } \mathrm{PR}=\text { progesterone receptor. } \\
\text { Factors shown above were chosen for examination using the multivariate model after } \\
\text { univariate analysis. Among age, structure, } \mathrm{PCR}, \mathrm{PN}, \mathrm{NG}, \mathrm{PR}, \mathrm{Ki67}, \mathrm{FOXA1} \text {, and } \mathrm{FOXO3a} \\
\text { (cytoplasm), the five factors with the lowest } P \text {-values were chosen for } \mathrm{DFS} \text { and } \mathrm{OS} \text {, respectively. } \\
\text { Bold entries indicate the } P \text {-values were judged as statistically significant. }{ }^{*} P<0.05 \text {; }{ }^{*} P<0.01 \text {. }\end{array}$} \\
\hline
\end{tabular}

non-pCR group, although the differences were not statistically significant by log-rank test (Figure $2 \mathrm{~A}$ and $\mathrm{B}$ ). In the same manner, FOXA1-low tumours $(n=34)$ tended to be associated with poorer patient outcomes than FOXA1-high tumours $(n=69)$ (Figure 2C and D). Moreover, when we compared pCR and non-pCR cases only in the FOXA1-low population, the curves became wider (Figure 2E and F), although the differences were still not significant based on the statistical method employed herein.

\section{DISCUSSION}

Despite recent controversy regarding the attainment of pCR in luminal tumours (Von Minckwitz et al, 2012), there could be a sub-population who would benefit from NAC in terms of prolonging survival (Fasching et al, 2011; Denkert et al, 2013; Horimoto et al, 2014). In fact, to date, all of our patients who 

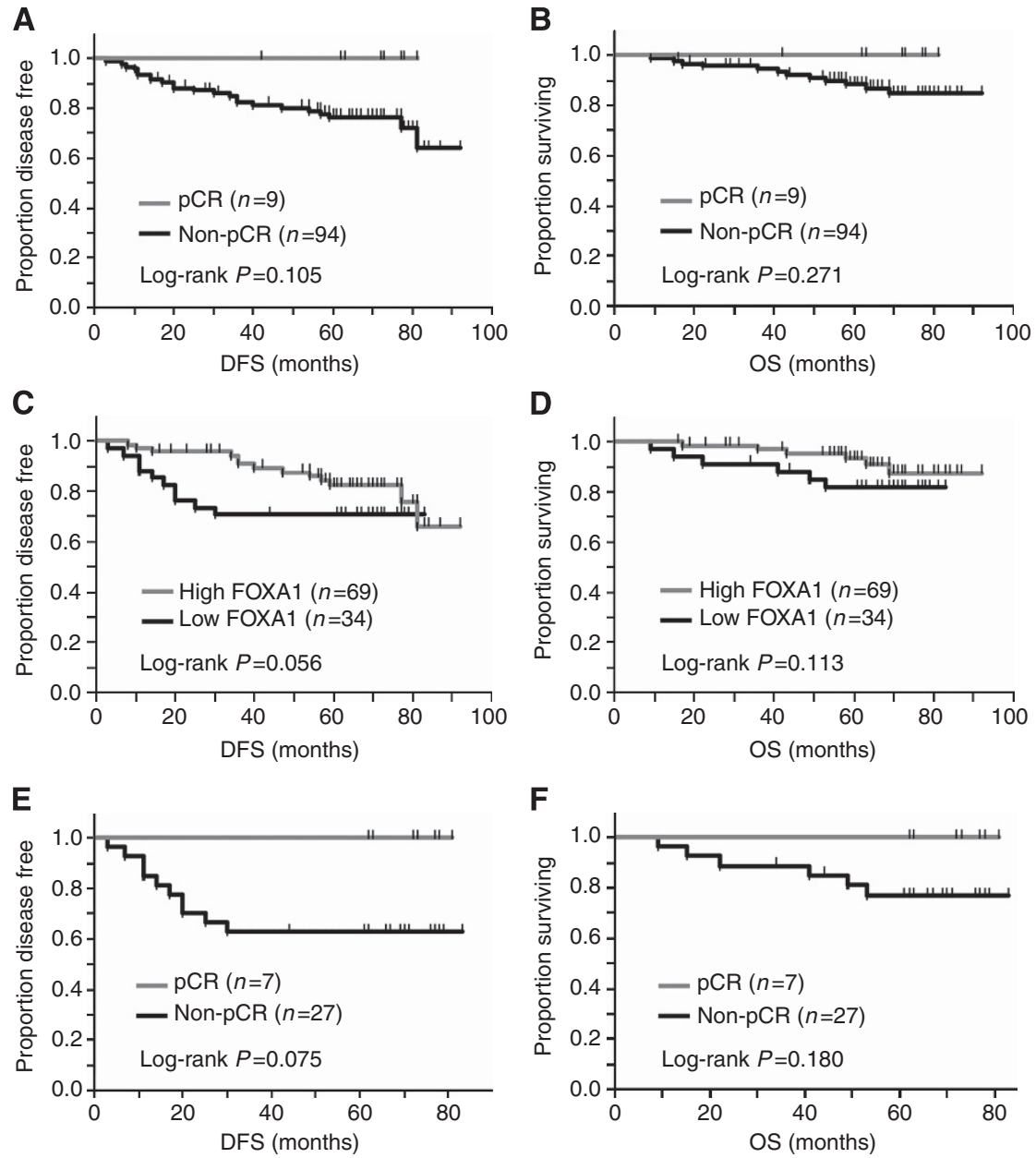

Figure 2. Kaplan-Meier curves of patient outcomes according to chemo-effect and FOXA1 expression. (A, B) Patients who obtained pCR ( $n=9$ ) showed better DFS and OS than the non-pCR group $(n=94)$, although the differences were not statistically significant by log-rank test. (C, D) In the same manner, FOXA1-low tumours $(n=34)$ tended to be associated with poorer patient outcomes than FOXA1-high tumours $(n=69)$. (E, F) When PCR and non-pCR cases were compared only in the FOXA1-low population $(n=34)$, the curves became wider, although the differences were still not significant based on the statistical method employed herein.

obtained pCR have remained free of recurrence. Despite the current widespread trend that favours avoiding chemotherapy in luminal HER2-negative patients, we believe that further investigation should be conducted to identify this sub-population more accurately. Neo-adjuvant chemotherapy might also increase possibilities for breast conserving surgery, another advantage for these patients.

Low expression of FOXA1 in patient samples was clearly related to a good response to NAC in this study. Our in vitro results using siRNA confirmed that the suppression of FOXA1 yields a better response to chemotherapy, though only paclitaxel was used and the results did not fully mimic clinical conditions. Although the mechanisms underlying the chemo-boosting effect are still unknown, Bernardo et al (2013) showed that FOXA1 regulates 'basal gene expression'. Thus, FOXA1 suppression could favour a basal propensity resulting in tumours being more sensitive to chemotherapy. Indeed, such a phenomenon was observed in MCF-7 cells in our in vitro experiments.

It is well known that luminal tumours with low FOXA1 carry a poor prognosis (Habashy et al, 2008; Thorat et al, 2008). In this study, high FOXA1-expressing tumours showed a trend towards being associated with better outcomes, although it was not statistically significant, corresponding to the results of previous studies. When outcomes were examined in FOXA1-low patients, the difference between pCR and non-pCR became more obvious. These results indicate that chemotherapy should be administered to this population with low FOXA1 expression because achieving pCR could be more meaningful. Adjuvant endocrine therapy was given to $98 \%$ of all study participants after surgery. Considering that low FOXA1 diminishes the efficacy of endocrine therapy (Fu et al, 2011; Hurtado et al, 2011; Robinson and Carroll, 2012; RossInnes et al, 2012), these results imply that the population showing good chemo-effects were salvaged from the poor effect of endocrine therapy with NAC. It is also noteworthy that we found FOXA1 to be related to patient outcomes independently of Ki67 expression, suggesting the potential usefulness of FOXA1 for determining chemotherapy indications in both luminal A-like and B-like tumours.

Interestingly, patients who had tumours with high FOXA1 expression tended to develop late recurrence. Among 24 recurrent cases, FOXA1 was high in 14 and these patients had longer DFS, with a median of 44 months (range: $8-98$ months) as compared with 16 months in the FOXA1-low group (3-30) (Table 5). Moreover, bone metastasis frequently occurred in the FOXA1-high group ( $79 \%, 11$ of 14 cases), while the rate was only $10 \%$ ( 1 of 10 cases) in the FOXA1-low group. Our results indicate that FOXA1 might be related to late recurrence, reflecting the observation that high FOXA1 tumours generally respond well to adjuvant endocrine therapy. Indeed, FOXA1 is a factor included in 
Table 5. FOXA1 expressions in 24 patients with recurrent disease

\begin{tabular}{l|c|c|}
\hline & FOXA1 low & FOXA1 high \\
\hline$n$ & 10 & 14 \\
\hline Age (median) & 51 & 53 \\
\hline DFS (median) & 16 & 44 \\
\hline Metastatic sites ${ }^{\text {a }}$ & 1 & 11 \\
\hline Bone & 3 & 3 \\
\hline Liver & 0 & 1 \\
\hline Lung & 6 & 3 \\
\hline Others & \\
\hline $\begin{array}{l}\text { Abbreviation: DFS = disease-free survival. } \\
\text { aAt the time when first recurrence was detected. }\end{array}$ \\
\hline
\end{tabular}

PAM50, the gene profiling kit, and it recently identified patients at high risk for late recurrence (Sestak et al, 2013). The mechanism is expected to be revealed in the near future with further investigation.

Its retrospective nature is the major limitation of this study. Also, a larger study is clearly needed to support our conclusion since no recurrences were observed in our pCR group. Moreover, there might be better ways than considering chemo-effects to determine the optimal cutoff value for judging whether a patient is FOXA1 positive.

Our study showed low FOXA1 expression to be associated with a good response to NAC in luminal HER2-negative breast cancer. Improved outcomes of these patients suggest that NAC should be recommended to those with low FOXA1 tumours. Further work is required to determine whether FOXA1 should be included in routine clinical examinations, to identify patients who would benefit from adjuvant chemotherapy.

\section{ACKNOWLEDGEMENTS}

We sincerely appreciate Ms Takako Ikegami and Ms Tomomi Ikeda from the Laboratory of Molecular and Biochemical Research, Research Support Centre and Ms Mutsumi Hara of the Atopy Research Centre at Juntendo University Graduate School of Medicine for their technical assistance. We also thank Dr Joe Matsuoka of the Clinical Research Support Centre at Juntendo University for advice on the statistical analysis.

\section{CONFLICT OF INTEREST}

The authors declare no conflict of interest.

\section{REFERENCES}

Badve S, Turbin D, Thorat MA, Morimiya A, Nielsen TO, Perou CM, Dunn S, Huntsman DG, Nakshatri H (2007) FOXA1 expression in breast cancercorrelation with luminal subtype A and survival. Clin Cancer Res 13: 4415-4421.

Bernardo GM, Bebek G, Ginther CL, Sizemore ST, Lozada KL, Miedler JD, Anderson LA, Godwin AK, Abdul-Karim FW, Slamon DJ, Keri RA (2013) FOXA1 represses the molecular phenotype of basal breast cancer cells. Oncogene 32: 554-563.

Denkert C, Loibl S, Müller BM, Eidtmann H, Schmitt WD, Eiermann W, Gerber B, Tesch H, Hilfrich J, Huober J, Fehm T, Barinoff J, Jackisch C, Prinzler J, Rüdiger T, Erbstößer E, Blohmer JU, Budczies J, Mehta KM, Von Minckwitz G (2013) Ki67 levels as predictive and prognostic parameters in pretherapeutic breast cancer core biopsies: a translational investigation in the neoadjuvant GeparTrio trial. Ann Oncol 24: 2786-2793.
Fasching PA, Heusinger K, Haeberle L, Niklos M, Hein A, Bayer CM, Rauh C, Schulz-Wendtland R, Bani MR, Schrauder M, Kahmann L, Lux MP, Strehl JD, Hartmann A, Dimmler A, Beckmann MW, Wachter DL (2011) Ki67, chemotherapy response, and prognosis in breast cancer patients receiving neoadjuvant treatment. BMC Cancer 11: 486.

Fu X, Huang C, Schiff R (2011) More on FOX News: FOXA1 on the horizon of estrogen receptor function and endocrine response. Breast Cancer Res 13: 307.

Goldhirsch A, Winer EP, Coates AS, Gelber RD, Piccart-Gebhart M, Thürlimann B, Senn H-J (2013) Personalizing the treatment of women with early breast cancer: highlights of the St Gallen International Expert Consensus on the Primary Therapy of Early Breast Cancer 2013. Ann Oncol 24: 2206-2223.

Goldhirsch A, Wood WC, Gelber RD, Coates AS, Thürlimann B, Senn H-J (2007) Progress and promise: highlights of the international expert consensus on the primary therapy of early breast cancer 2007. Ann Oncol 18: 1133-1144.

Habashy HO, Powe DG, Rakha EA, Ball G, Paish C, Gee J, Nicholson RI, Ellis IO (2008) Forkhead-box A1 (FOXA1) expression in breast cancer and its prognostic significance. Eur J Cancer 44: 1541-1551.

Hisamatsu Y, Tokunaga E, Yamashita N, Akiyoshi S, Okada S, Nakashima Y, Aishima S, Morita M, Kakeji Y, Maehara Y (2012) Impact of FOXA1 expression on the prognosis of patients with hormone receptor-positive breast cancer. Ann Surg Oncol 19: 1145-1152.

Ho K-K, Mcguire VA, Koo C-Y, Muir KW, De Olano N, Maifoshie E, Kelly DJ, Mcgovern UB, Monteiro LJ, Gomes AR, Nebreda AR, Campbell DG, Arthur JSC, Lam EW-F (2012) Phosphorylation of FOXO3a on Ser-7 by p38 promotes its nuclear localization in response to doxorubicin. $J$ Biol Chem 287: 1545-1555.

Ho K-K, Rosivatz E, Gunn RM, Smith MEB, Stavropoulou AV, Rosivatz E, Numbere MG, Wong JB, Lafitte VGH, Behrendt JM, Myatt SS, Hailes HC, Woscholski R, Lam EWF (2009) The novel molecule 2-[5-(2-chloroethyl)2-acetoxy-benzyl]-4-(2-chloroethyl)-phenyl acetate inhibits phosphoinositide 3-kinase/Akt/mammalian target of rapamycin signalling through JNK activation in cancer cells. FEBS J 276: 4037-4050.

Ho KK, Myatt SS, Lam EWF (2008) Many forks in the path: cycling with FoxO. Oncogene 27: 2300-2311.

Horimoto Y, Arakawa A, Tanabe M, Sonoue H, Igari F, Senuma K, Tokuda E, Shimizu H, Kosaka T, Saito M (2014) Ki67 expression and the effect of neo-adjuvant chemotherapy on luminal HER2-negative breast cancer. $B M C$ Cancer 14: 550 .

Hurtado A, Holmes KA, Ross-Innes CS, Schmidt D, Carroll JS (2011) FOXA1 is a key determinant of estrogen receptor function and endocrine response. Nat Genet 43: 27-33.

Kawase M, Toyama T, Takahashi S, Sato S, Yoshimoto N, Endo Y, Asano T, Kobayashi S, Fujii Y, Yamashita H (2013) FOXA1 expression after neoadjuvant chemotherapy is a prognostic marker in estrogen receptor-positive breast cancer. Breast Cancer; e-pub ahead of print 16 June 2013; doi:10.1007/s12282-013-0482-2.

Liu Y-N, Lee W-W, Wang C-Y, Chao T-H, Chen Y, Chen JH (2005) Regulatory mechanisms controlling human E-cadherin gene expression. Oncogene 24: 8277-8290.

Peck B, Ferber EC, Schulze A (2013) Antagonism between FOXO and Myc regulates cellular powerhouse. Front Oncol 3: 96.

Peppercorn J, Perou CM, Carey LA (2008) Molecular subtypes in breast cancer evaluation and management: divide and conquer. Cancer Invest 26: 1-10.

Robinson J, Carroll J (2012) FoxA1 is a key mediator of hormonal response in breast and prostate cancer. Front Endocrinol 3: 68.

Ross-Innes CS, Stark R, Teschendorff AE, Holmes KA, Ali HR, Dunning MJ, Brown GD, Gojis O, Ellis IO, Green AR, Ali S, Chin S-F, Palmieri C, Caldas C, Carroll JS (2012) Differential oestrogen receptor binding is associated with clinical outcome in breast cancer. Nature 481: 389-393.

Sørlie T, Tibshirani R, Parker J, Hastie T, Marron JS, Nobel A, Deng S, Johnsen H, Pesich R, Geisler S, Demeter J, Perou CM, Lønning PE, Brown PO, Børresen-Dale A-L, Botstein D (2003) Repeated observation of breast tumor subtypes in independent gene expression data sets. Proc Natl Acad Sci 100: 8418-8423.

Sasahara M, Matsui A, Ichimura Y, Hirakata Y, Murata Y, Marui E (2014) Overexpression of androgen receptor and Forkhead-box A1 protein in apocrine breast carcinoma. Anticancer Res 34: 1261-1267.

Sestak I, Dowsett M, Zabaglo L, Lopez-Knowles E, Ferree S, Cowens JW, Cuzick J (2013) Factors predicting late recurrence for estrogen receptor-positive breast cancer. J Natl Cancer Inst 105: 1504-1511. 
Thorat MA, Marchio C, Morimiya A, Savage K, Nakshatri H, Reis-Filho JS, Badve S (2008) Forkhead box A1 expression in breast cancer is associated with luminal subtype and good prognosis. J Clin Pathol 61: 327-332.

Tominaga N, Naoi Y, Shimazu K, Nakayama T, Maruyama N, Shimomura A, Kim SJ, Tamaki Y, Noguchi S (2012) Clinicopathological analysis of GATA3-positive breast cancers with special reference to response to neoadjuvant chemotherapy. Ann Oncol 23: 3051-3057.

Von Minckwitz G, Untch M, Blohmer JU, Costa SD, Eidtmann H, Fasching PA, Gerber B, Eiermann W, Hilfrich J, Huober J, Jackisch C, Kaufmann M, Konecny GE, Denkert C, Nekljudova V, Mehta K, Loibl S (2012) Definition and impact of pathologic complete response on prognosis after neoadjuvant chemotherapy in various intrinsic breast cancer subtypes. J Clin Oncol 30: 1796-1804.
Williamson EA, Wolf I, O’kelly J, Bose S, Tanosaki S, Koeffler HP (2005) BRCA1 and FOXA1 proteins coregulate the expression of the cell cycle-dependent kinase inhibitor p27Kip1. Oncogene 25: 1391-1399.

Wolf I, Bose S, Williamson EA, Miller CW, Karlan BY, Koeffler HP (2007) FOXA1: Growth inhibitor and a favorable prognostic factor in human breast cancer. Int J Cancer 120: 1013-1022.

This work is published under the standard license to publish agreement. After 12 months the work will become freely available and the license terms will switch to a Creative Commons AttributionNonCommercial-Share Alike 3.0 Unported License.

Supplementary Information accompanies this paper on British Journal of Cancer website (http://www.nature.com/bjc) 